\title{
Test Bench Simulator for Heart Valves
}

\author{
Gianluigi Petrogalli, ${ }^{1, a}$ and Maurizio Mor $^{1}$ \\ ${ }^{1}$ Polibrixia, R\&D Department, 25123 Brescia, Italy
}

\begin{abstract}
The objective of this research is the creation of a testing bench prototype for comparing different types of heart valves, taking into account the variability of some important parameters involved in cardiovascular events. Thanks to performed tests and to obtained data, the comparison between the different valves allows physicians to make the most appropriate choice of heart valve for each patient. The study is still in preliminary stage: it is necessary to do many tests in order to obtain a large amount of data with which it is possible to proceed with the development and implementation of a testing bench stable and easily programmable.
\end{abstract}

\section{Introduction}

The objective of this research is the creation of a testing bench prototype for comparing different types of heart valves, taking into account the variability of some important parameters involved in cardiovascular events [1].

The high simplicity of the device allows a direct pressure and flow acquisition and processing, thanks to an appropriate software.

A linear motor is used to simulate the heartbeat and, thanks to changes in the parameters of a PID controller [2], is calibrated to reproduce the law of motion [3-7] taken from the literature [1]: this law was made more suitable for our use eliminating discontinuities and traits not connected.

For acquiring pressures and flows is adopted a measurement system that complies with UNI EN ISO 5840:2006 "Cardiovascular implants - Cardiac valve prostheses" [8].

\section{The blood model}

The blood is a connective tissue composed of both liquid part and particles that are in suspension. The first, called emulsion part, is represented by the plasma, and the second, called suspension part, includes red and white blood cells.

The plasma is commonly treated as a homogeneous and incompressible fluid with newtonian behavior. It has a dynamic viscosity of $0.0012-0.0016 \mathrm{~kg} / \mathrm{ms}$ at $37^{\circ} \mathrm{C}$ and a specific weight equal to 1025-1028 times compared to water [9].

On the other hand the blood, with all its elements, cannot be considered as absolutely newtonian: from literature [10-12] it is known that its behavior depends on both the section of the duct in which it flows and heartbeat frequency.

\footnotetext{
${ }^{\mathrm{a}}$ Corresponding author : gianluigi.petrogalli@polibrixia.it
} 


\section{MATEC Web of Conferences}

At low frequencies $(<10 \mathrm{~s}-1)$ it is non-newtonian, following the laws of Bingham [9] at high frequencies $(60-100 \mathrm{~s}-1)$ is typically newtonian and for midrange frequencies is thixotropic (liquid-gel transitions may occur).

During normal function of cardiovascular system, we can consider the blood as essentially newtonian with a viscosity of approximately four times larger than water.

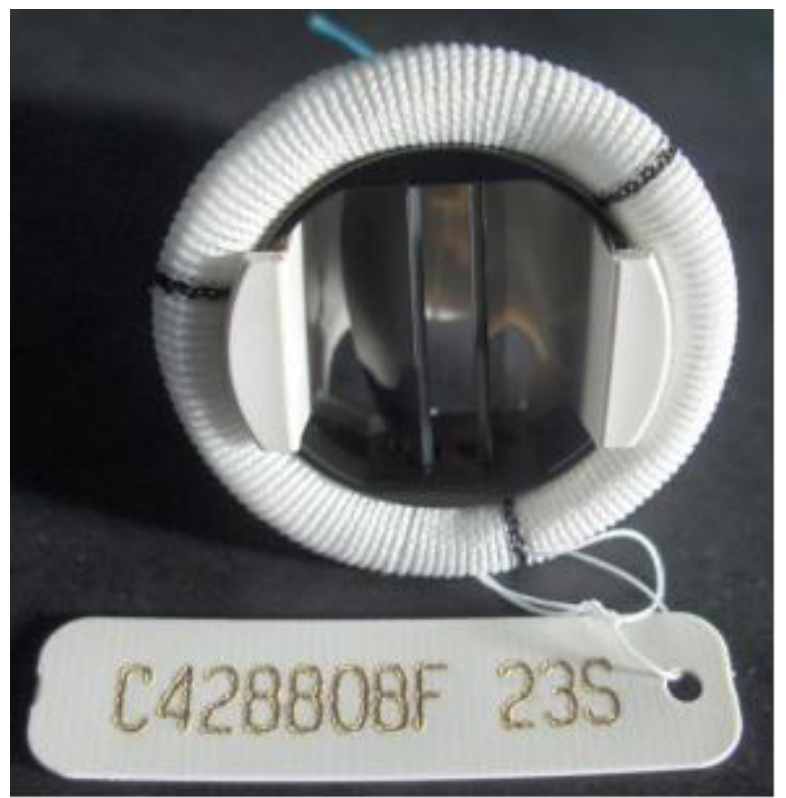

Figure 1. The artificial aortic valve installed in the test bench: the section has a diameter of $23 \mathrm{~mm}$. The valve is manufactured from SulzerMedica ${ }^{\circledR}$.

For the development of testing bench and for the design of various components is used the mathematical model of Walburn - Schneck (1), whose constitutive law of viscosity of the blood is shown below.

$$
\mu=c_{1} \cdot e^{c_{2} \cdot H t}\left[e^{c_{4} \cdot\left(\frac{T P M A}{H t^{2}}\right)}\right] \cdot \dot{\gamma}^{-c_{3} \cdot H t}
$$

Where:

$-\mu$ is the blood's viscosity;

-TPMA represents the content of proteins, except albumin;

-Ht is the percentage of hematocrit;

$-\mathrm{c} 1, \mathrm{c} 2, \mathrm{c} 3$ and $\mathrm{c} 4$ are characteristic constants (tabulated);

$-\Upsilon$ typical value depending on pressure, flow and geometric dimensions of the duct.

The normal $\mathrm{Ht}$ values for a man must be included in the range $42 \%-53 \%$, while for a woman between $37 \%$ and $52 \%$ : we chose a Ht value 0.399 . The parameter TPMA was set equal to 0.0032 , selecting $8 \%$ of blood's protein of the plasma constituents and considering that albumin represents $60 \%$ of total proteins [13].

The great advantage of this law is that allows to compare physiologic parameters [14], such as the hematocrit or TPMA [1], with mechanical parameters as the viscosity $\mu$ of the blood, the pressure and 
flow. The test bench is calibrated on the basis of parameters that are easily recognizable by doctors: we can also implement a programming mode using the instruments for the measurement of blood parameters.

\section{Testbench}

The primary target of testing bench is to acquire the variables that describe the dynamic behavior of the fluid during the heartbeat [8].

In order to optimize the functionality of the device, in the design phase, was considered the real flow dynamics blood pumped by the heart [1]; with this approach, the attention is focused only on the most interesting aspects.

The tests were performed on a mechanical aortic valve, which is usually located in the left part of the heart and more precisely in the left ventricle.

The left ventricle, isolated from the rest of the organ, can be modeled as a simple effect pump with inlet and outlet of the fluid controlled by two one-way valves [15-22].

As shown in Fig. 1 and Fig. 2, the heartbeat is reproduced using a linear motor [23-28] connected to a hydraulic cylinder with double effect: in this way, with a suitable law of motion is possible to flow the fluid within the circuit, and to adjust the heart's frequency.

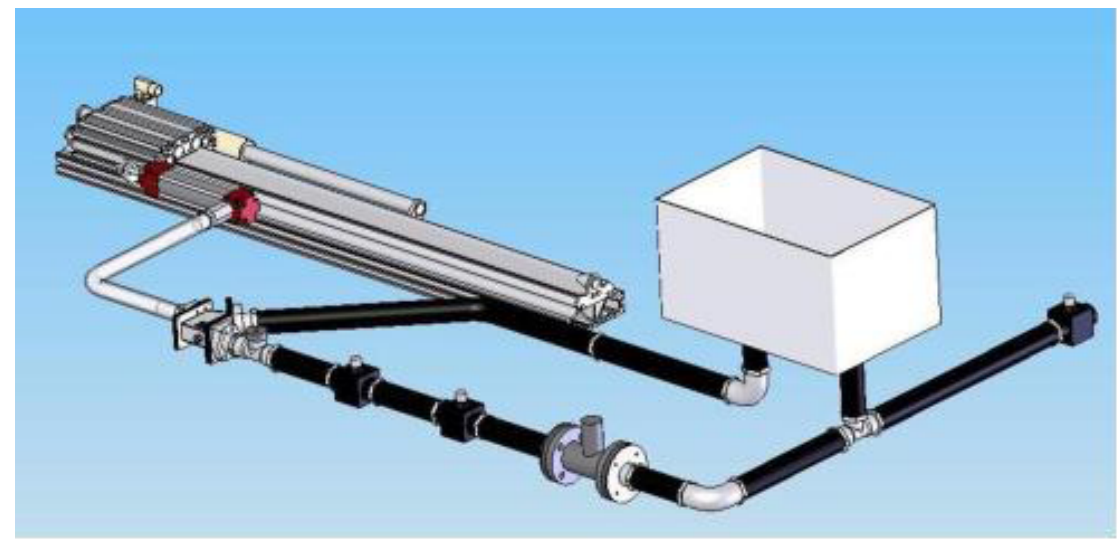

Figure 2. The design of testing bench consists of a linear motor, "heart" group and sensors.

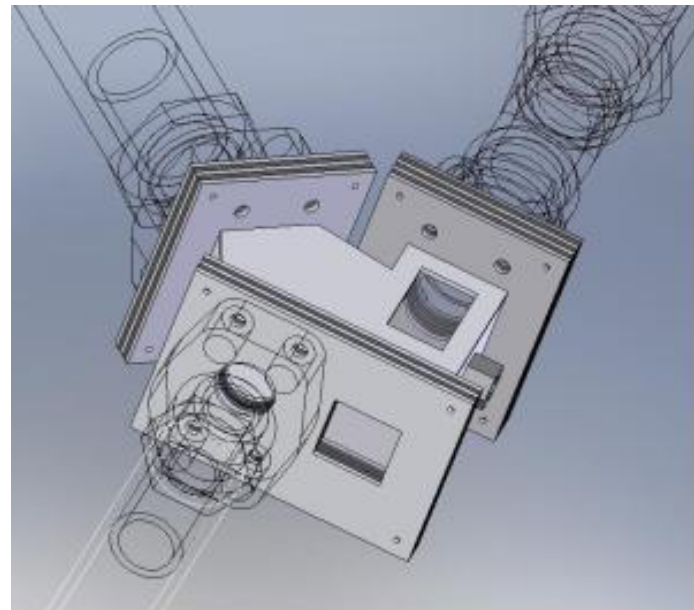

Figure 3. Detail of "heart" group, made of aluminum or plastic, in which the commercial heart valve is positioned. 


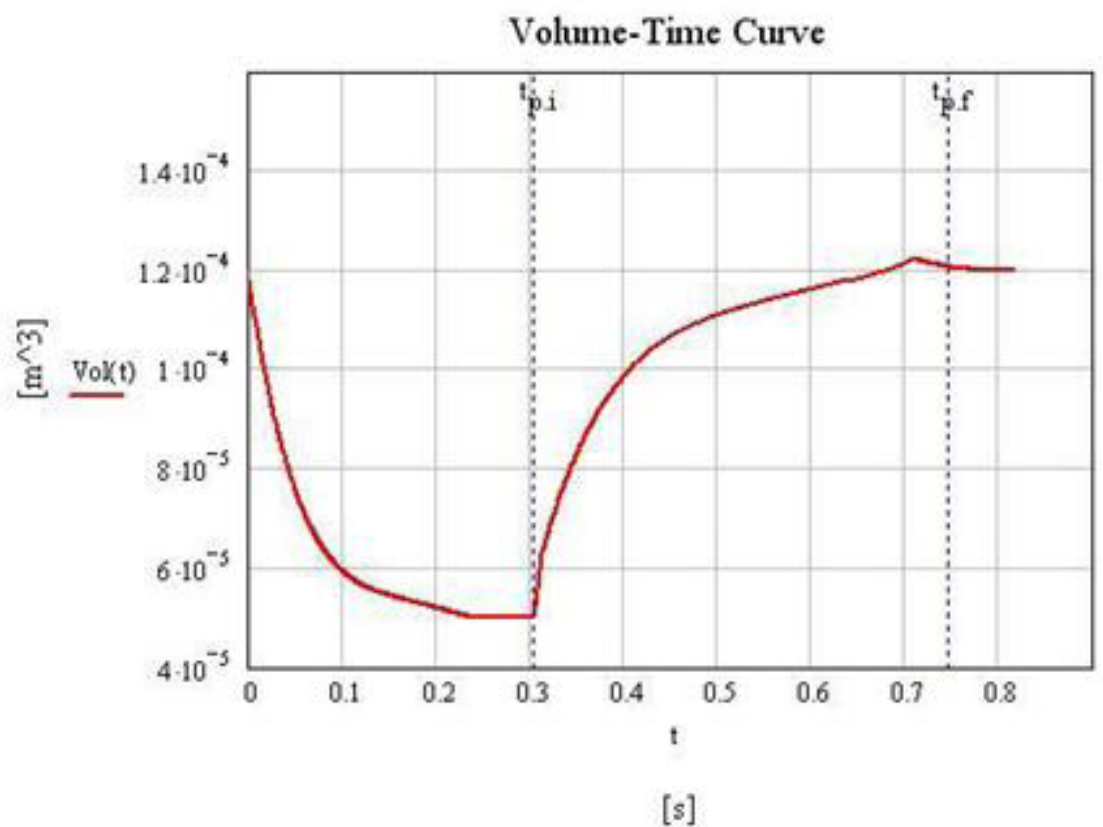

Figure 4. Curve of volume of fluid through the left ventricle experimentally acquired.

The parameters considered for linear motor choice are:

-the force required to move the blood's mass;

-the speed of fluid;

-the necessary acceleration for movement.

Fig. 4 shows a typical time-fluid volume curve for the left ventricle of a human heart [1]: it's easy to observe that there are discontinuities in transition from suction phase to sending phase and therefore it cannot be set directly to linear motor [29-32].

It was necessary to interpolate it through fourth order polynomials.

Under the literature advice [33-43], the linear motor should run easily with a law of motion as smooth as possible in order to avoid vibrations and other undesired effects associated with the presence of compliances and inertias [24, 44-46].

For measuring the pressure and flow were used respectively the sensor SEN-3284 B045 by KOBOLD ( $)$ and the flowmeter FLOMAG 3000 (model A3); signals were acquired with NI USB-6009 by National Instrument and signal processing was performed with a dedicated program developed with Labview [47].

\section{Experimental results and conclusions}

Kinematical [48-55] and dynamical [56-58] aspects of the system are related to the linear motor's calibration $[59,60]$ that is performed by changing PID parameters and by overlapping the obtained law of motion on the desired one, for a heart rate of 60 beats per minute.

When the deviation between two laws is acceptable, durability tests are performed by varying heart's frequency or by setting a random frequency and then by analyzing the heart valve's behaviour.

Since the obtained law of motion was composed of five parts connected by means of a polynomial curve, the algorithm for automatic calibration was not easily obtainable. For these reasons it was 
decided to proceed experimentally by adjusting first of all the proportional and integrative components and then the derivative part.

A not correct viscosity of the fluid, or an inadequate law of motion can cause undesired effects that generate instability within the device, until the engine failure [61].

In executed tests a motor's stroke deviation of $1 \mathrm{~mm}$ was considered acceptable: in fact, a greater error could create vibrations, abnormal openings of the valve and errors in measuring instruments.

The objective of this research is to carry out a testing bench for various commercial heart valves, by simulating the heartbeat through a linear motor and by adjusting the law of motion with respect to the fluid properties.

Thanks to performed tests and to obtained data, the comparison between the different valves allows the doctors to make the most appropriate choice of heart valve for each patient.

The study is still in preliminary stage: it is necessary to do many tests in order to obtain a large amount of data with which it is possible to proceed with the development and implementation of a testing bench stable and easily programmable.

\section{References}

[1] J. C. Shryock and L. Belardinelli, American Journal of Cardiology, 79, 2-10, 1997

[2] A. Emadi, Y. J. Lee, and K. Rajashekara, IEEE Transactions on Industrial Electronics, 55, 2237-2245, 2008

[3] A. Borboni, R. Bussola, R. Faglia, and M. Tiboni, Proceedings of the 2004 Eleventh World Congress in Mechanism and Machine Science, 1, 1-5, 2004

[4] M. Antonini, A. Borboni, R. Bussola, and R. Faglia, Proceedings of 8th Biennial ASME Conference on Engineering Systems Design and Analysis ESDA2006, 2006, 1-8, 2006

[5] M. Antonini, A. Borboni, R. Bussola, and R. Faglia, Proceedings of 8th Biennial ASME Conference on Engineering Systems Design and Analysis ESDA2006, 2006, 1-8, 2006

[6] A. Borboni, R. Bussola, R. Faglia, P. L. Magnani, and A. Menegolo, Journal of Mechanical Design, Transactions of the ASME, 130, 0823011-0823016, 2008

[7] A. Borboni, M. Lancini, and R. Faglia, ASME 2014 12th Biennial Conference on Engineering Systems Design and Analysis ESDA 2014, 2, 1-7, 2014

[8] B. Heublein, R. Rohde, V. Kaese, M. Niemeyer, W. Hartung, and A. Haverich, Heart, 89, 651-656, 2003

[9] J. Shih, H. J. Kim, and C. A. Taylor, Proceedings of the ASME Summer Bioengineering Conference, SBC2008, 2009, 317-318

[10] G. Gerosa, V. Tarzia, G. Rizzoli, and T. Bottio, Journal of Thoracic and Cardiovascular Surgery, 131, 1058-1064.e2, 2006

[11] A. Giovannelli, G. Alessandri, A. Rama, I. Gandjbakhch, G. Rondoni, and N. Alessandri, European Review for Medical and Pharmacological Sciences, 12, 303-308, 2008

[12] M. K. Sharp and R. K. Dharmalingam, ASAIO Journal, 45, 535-540, 1999

[13] M. Koeppen, T. Eckle, and H. K. Eltzschig, Anesthesiology, 2015

[14] G. Taveggia, J. H. Villafañe, F. Vavassori, C. Lecchi, A. Borboni, and S. Negrini, Journal of Manipulative and Physiological Therapeutics, 37, 242-252, 2014

[15] M. Tiboni, A. Borboni, M. Mor, and D. Pomi, Proceedings of the Institution of Mechanical Engineers. Part I: Journal of Systems and Control Engineering, 225, 443-451, 2011

[16] G. H. Feng and E. S. Kim, Journal of Micromechanics and Microengineering, 14, 429-435, 2004

[17] A. Borboni, F. Aggogeri, and R. Faglia, International Journal of Advanced Robotic Systems, 10, 1-10, 2013

[18] P. Q. Su and Z. H. Deng, Applied Mechanics and Materials 318, 15-20, 2013

[19] V.V Okrepilov, V.N. Krutikov, G.I. El'kin, Measurement Techniques, 57 (2),109-116 (2014)

[20] V.V Okrepilov, Studies on Russian Economic Development, 24(1), 35-42 (2013) 
[21] V.V Okrepilov, Standarty i Kachestvo, 10, 52-55 (2005)

[22] G. I. Grinfeldi, A. S. Gorshkov, and N. I. Vatin, Advanced Materials Research 941-944, 7

[23] A. Borboni, F. Aggogeri, N. Pellegrini, and R. Faglia, Advanced Materials Research, 590, 405-410, 201286-799, 2014

[24] F. Aggogeri, A. Borboni, and R. Faglia, Applied Mechanics and Materials, 373-375, 130133,2013

[25] A. Borboni, R. Faglia, and M. Palpacelli, MESA 2014 - 10th IEEE/ASME International Conference on Mechatronic and Embedded Systems and Applications, 1, 1-7, 2014

[26] A. Borboni, S. Pandini, D. Cambiaghi, M. Lancini, R. Adamini, R. Faglia, et al., ASME 2014 12th Biennial Conference on Engineering Systems Design and Analysis, ESDA 2014, 3, 1-6, 2014

[27] S. Pandini, A. Borboni, I. Bodini, D. Vetturi, D. Cambiaghi, K. Paderni, et al., AIP Conference Proceedings, 1599, 306-309, 2014

[28] S. Pandini, T. Riccò, A. Borboni, I. Bodini, D. Vetturi, D. Cambiaghi, et al., Journal of Materials Engineering and Performance, 23, 2545-2552, 2014

[29] G. D. Buckberg, M. Castellá, M. Gharib, and S. Saleh, European Journal of Cardio-thoracic Surgery, 29, S98-S106, 2006

[30] C. Dragan, A. Samuila, S. Das, D. Iancu, M. Bilici, and L. Dascalescu, Journal of Electrostatics, 67, 184-188, 2009

[31] H. Mamori, K. Fukagata, and J. Hoepffner, Physical Review E - Statistical, Nonlinear, and Soft Matter Physics, 81, 2010

[32] H. Rau, S. Brody, C. Droste, and A. Kardos, European Journal of Applied Physiology and Occupational Physiology, 67, 26-29, 1993

[33] A. Borboni, D. De Santis, and R. Faglia, Proceedings of 8th Biennial ASME Conference on Engineering Systems Design and Analysis ESDA2006, 2006, 1-8, 2006

[34] A. Borboni, F. Aggogeri, N. Pellegrini, and R. Faglia, Advanced Materials Research, 590, 399-404, 2012

[35] F. Aggogeri, A. Borboni, R. Faglia, A. Merlo, and S. De Cristofaro, Applied Mechanics and Materials, 336-338, 1170-1173, 2013

[36] A. Borboni and R. Faglia, Journal of Applied Mechanics Transactions ASME, 80, 1-7, 2013

[37] A. Borboni and R. Faglia, Procedia Engineering, 2014, 1378-1381

[38] Z. Guoyong, Z. Yugang, and H. Ronggguo, Applied Mechanics and Materials 29-32, 20022007,2010

[39] M. H. Korayem, M. Nazemizadeh, and H. R. Nohooji, International Journal of Advanced Robotic Systems, 9, 2012

[40] T. S. Lee and Y. J. Lin, International Journal of Advanced Manufacturing Technology, 15, 640-648, 1999

[41] J. Mattmüller and D. Gisler, International Journal of Advanced Manufacturing Technology, 45, 1007-1016, 2009

[42] I. Storey, A. Bourmistrova, and A. Subic, Proceedings of the Institution of Mechanical Engineers, Part C: Journal of Mechanical Engineering Science, 226, 2656-2673, 2012

[43] A. Borboni and M. Lancini, Journal of Vibration and Acoustics, Transactions of the ASME, 137, 1-9, 2015

[44] A. Borboni, D. De Santis, and R. Faglia, ASME 2010 10th Biennial Conference on Engineering Systems Design and Analysis ESDA2010, 2, 99-106, 2010

[45] A. Borboni and D. De Santis, Meccanica, 49, 1327-1336, 2014

[46] A. Borboni, R. Faglia, and M. Mor, ASME 2014 12th Biennial Conference on Engineering Systems Design and Analysis ESDA 2014, 1, 1-10, 2014

[47] M. Tsukiji, N. Watanabe, Y. Yamaura, N. Okahashi, K. Obase, Y. Neishi, et al., Journal of the American Society of Echocardiography, 21, 43-46, 2008

[48] A. Borboni, Proc of the IEEE International Conference on Fuzzy Systems, 1, 336-339, 2001 
[49] G. Resconi, A. Borboni, R. Faglia, and M. Tiboni, Lecture Notes in Computer Science, 2178 LNCS, 352-368, 2001

[50] C. Amici, A. Borboni, P. L. Magnani, and D. Pomi, Proceedings of EUCOMES 2008 - The 2nd European Conference on Mechanism Science, 2008, 479-485, 2009

[51] A. Borboni, F. Aggogeri, and R. Faglia, ASME 2014 12th Biennial Conference on Engineering Systems Design and Analysis ESDA 2014, 3, 1-10, 2014

[52] J. Denton and J. B. Cronin, Journal of Strength and Conditioning Research, 20, 528-534, 2006

[53] A. C. Fisher, Clinical Hemorheology, 5, 61-69, 1985

[54] G. Guidoboni, R. Glowinski, N. Cavallini, S. Canic, and S. Lapin, Applied Mathematics Letters, 22, 684-688, 2009

[55] T. T. Nguyen, Y. Biadillah, R. Mongrain, J. Brunette, J. C. Tardif, and O. F. Bertrand, Journal of Biomechanical Engineering, 126, 529-535, 2004

[56] C. Amici, A. Borboni, R. Faglia, D. Fausti, and P. L. Magnani, IEEE/RSJ International Conference on Intelligent Robots and Systems IROS, 2008, 735-740, 2008

[57] C. Amici, A. Borboni, P. L. Magnani, and D. Pomi, Proceedings of EUCOMES 2008 - The 2nd European Conference on Mechanism Science, 2008, 487-493, 2009

[58] C. Amici, A. Borboni, and R. Faglia, Advances in Mechanical Engineering, 2, 1-9, 2010

[59] H. H. Mu, Y. F. Zhou, X. Wen, and Y. H. Zhou, Mechatronics, 19, 577-585, 2009

[60] F. Aggogeri, A. Borboni, A. Merlo, and N. Pellegrini, Advanced Materials Research, 590, $252-257,2012$ 